Fahrenheits Scala

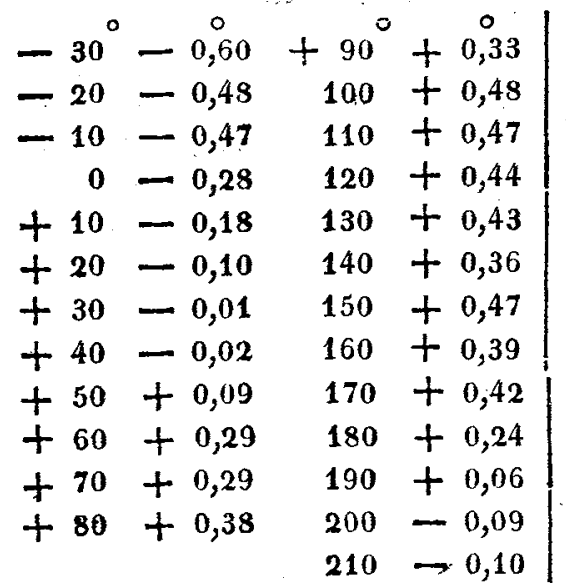

Celsius Scala.

\begin{tabular}{rr|rr|rr}
${ }^{\circ}-30$ & $+0,24$ & -30 & $+0,42$ & $-30+0,12$ \\
-20 & $+0,16$ & -20 & $+0,14$ & -20 & $+0,06$ \\
-10 & 0,00 & -10 & $+0,09$ & -10 & $-0,12$ \\
0 & 0,00 & 0 & 0,00 & 0 & 0,00 \\
+10 & $+0,09$ & +10 & $+0,07$ & $+10-0,07$ \\
$+20-0,01$ & +20 & $+0,10$ & $20-0,11$ \\
30 & $+0,03$ & 30 & $-0,08$ & $30+0,02$ \\
$40-0,01$ & 40 & $-0,01$ & $40-0,01$ \\
$50-0,01$ & $50-0,26$ & $50-0,04$ \\
$60-0,24$ & $60-0,22$ & $60-0,07$ \\
$70-0,26$ & $70-0,21$ & $70+0,08$ \\
$80-0,36$ & $80-0,25$ & $80-0,06$ \\
$90-0,17$ & $90-0.14$ & $90+0,09$ \\
100 & 0,00 & 100 & 0,00 & 100 & 0,00
\end{tabular}

Ein Grad beträgt auf den hier geprüften Thermometern ungefähr 0,7 Par. Lin. Wenn also auch der Wissenschaftsmann sein Thermometer lieber selbst prüfen wird, so denke ich mufs dem blufsen Liebhaber es doch äusserst ungenehm seyn, so genaue Thermometer zu erhalten. Daher wïrden Sie dem Publicum, glaube ich, einen eben so grofsen Dienst erzeigen, als meinem Freunde Bäcker, wenn Sie vielleicht in len Hamburger Zeitungen diese
Thermomeler bekannt machen wollten. Bäcker hat meh. rere hundert von seinen Thermometern in Hamburg, die er dort zu veränfsern gedenkt; mit meinem nächsten Schreiben werde ich Ihnen die Addresse aufgeben *).

*) Ich werde mit Vergnügen die Commissionen auf diese Thermometer besorgen, die mir von Liebhabern aufgetragen werden möchteu.

Fr. Argelander.

Auszug aus einem Briefe des Herrn Professors Argelander, Directors der Sternwarte in Åbo, an Herrn Th. Clausen. Åbo 1825. Aug. 27.

Ich fand den Bielaschen Cometen denselben Tag, als die Nachricht hier ankam, und obgleich er sehr grofs und unbestimmt erscheint, so glaube ich doch, dafs die fol-

genilen Beobachtungen am 5füfsigen Fraunhofer Zutrauen vérdienen:

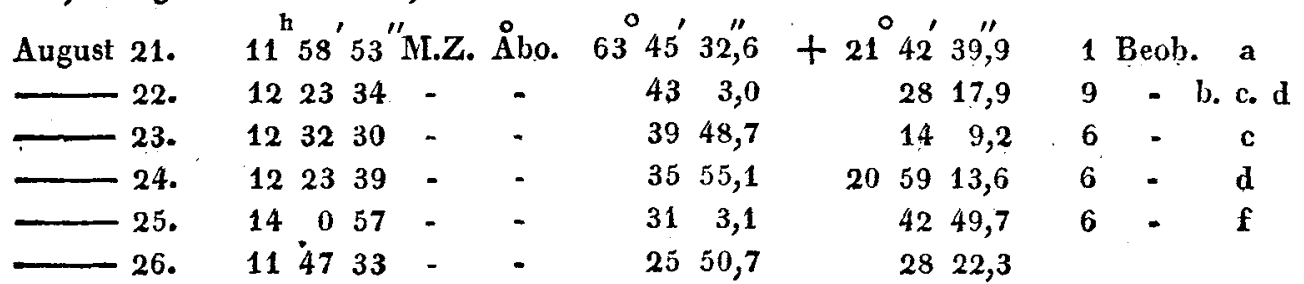

Den Stern a halte ich für Hist. Cél. p. 36. 1793. Oct. 28. $4^{\text {h }} 13^{\prime} 48^{\prime \prime}, 5$; man mufs dann aber die Z.D. $27^{\circ} 34^{\prime} 30^{\prime \prime}$ stait $27^{\circ} 3^{\prime} 30^{\prime \prime}$ lesen. So verlangen es 8 gut gelungene Vergleichungen mit $67-\mho$; die andern Sterne sind Piazzische: die scheinbaren Positionen habe ich angenommen:

$$
\begin{aligned}
& \text { a ..............6 } 63^{\circ} 28^{\prime} 41^{\prime \prime}, 3+21^{\circ} 19^{\prime} 31,6 \\
& \text { b...67 Tauri .... } 634553,7+214737,0
\end{aligned}
$$

$$
\begin{aligned}
& \text { c... P.IV. } 82 \ldots .64^{\circ} 25^{\prime} 16^{\prime \prime}, 3+21^{\circ} 13^{\prime} 24,6 \\
& \text { d... P.IV. } 76 \ldots 635954,7+2140,8 \\
& \text { f ... P.IV. } 48 \ldots 624956,5+204550,1
\end{aligned}
$$

Die letzte Beobachtung beruht auf Allignements, indem der Mondschein und das unbeständige Wetter nur liese erlaublen; ich halte sie aber wegen der Nähe der Sterne für sehr sicher. 
Nicht so günstig ist der Himmel den Beobachlungen des Ponsschen Cometen gewesen. Aufser den beiden August $22014^{\text {h }} 3^{\prime} 27^{\prime \prime} \mathrm{M} Z$. Abo, $120^{\circ} 7^{\prime} 46^{\prime \prime}$

24. $134013-\quad$ - 124730,9

d kommt vor in der Hist. Cél. p. 144. 1795 Febr. 16. $9^{\mathrm{m}} 7^{\text {h }} 52^{\prime} 27^{\prime \prime}, 5$. $20^{\circ} 39^{\prime} 19^{\prime \prime}$. Die scheinbare Position berechnete ich $2 u 118^{\circ} 30^{\prime} 20^{\prime \prime}, 1+28^{\circ} 5^{\prime} 11^{\prime \prime}, 8$. g findet sich $3 \mathrm{mal}$ in dër Hist. Cél., nemlich p. 146. 1795 März 20.

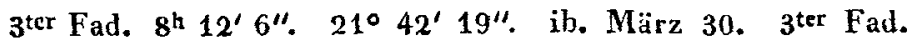
$8^{\text {h }} 11^{\prime} 50^{\prime \prime}, 5.21^{\circ} 42^{\prime} 9$. und 286. 1797 März 22. $3^{\text {ter }}$ Fad. $8^{\text {h }} 12^{\prime} 1^{\prime \prime}$. $21^{\circ} 42^{\prime} 18^{\prime \prime}$. Der Stern scheint aber eine be-
Beobachtungen, die ich vor 8 Tagen Herrn Professor Schumacher mittheilte, habe ich nur folgende erhalten:

$+28^{\circ} 5^{\prime} 40,3 \ldots 6$ Beobb. d. $-i^{\prime} 49,0+59,5$

$+26579,7 \ldots 7$ - g. $-131,5+52,3$

deutende eigne Bewegung in Decl. zu haben; ich nahm die AR. aus der Hist. Cél., die Decl. nach meiner Beobachlung, nemlich Pos, app. $123^{\circ} 27^{\prime} 22^{\prime \prime}, 2+27^{\circ} 0^{\prime} 5^{\prime \prime}, 9$. Der Comet ist übrigens so lichtstark, dafs man ihn ungeachtet des Mondscheins recht gut würde beobachten können, wenn nur der Horizont freier von Wolken wäre.

\section{Beobachtungen des letzten Cometen vom Jahre 1824 auf der Sternwarte in Dorpat angestellt.}

Die nachstehenden Beobachtungen sind mit einem Kreismikrometer des 5 füfsigen Achromats von Troughton angestellt. Die verglichenen Sterne sind am Meridiankreise beslimmt worden. Die Buchstaben $\mathrm{N}$ und $\mathrm{S}$ bey der Declination zeigen an, auf welche Seite des Centri des Kreises der Komet durchgegangen ist. Die mit einem Siern bezeichneten Resultate sind die wegen der Lage der Chorden unsicheren.

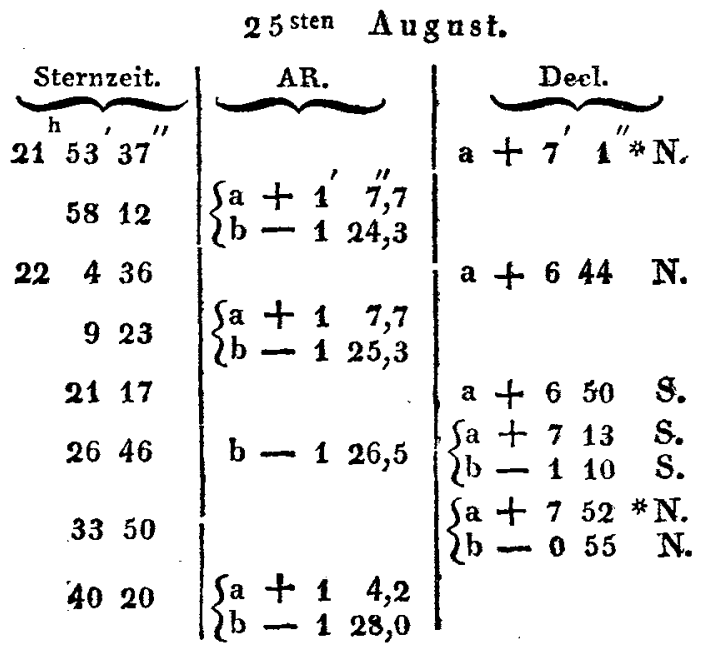

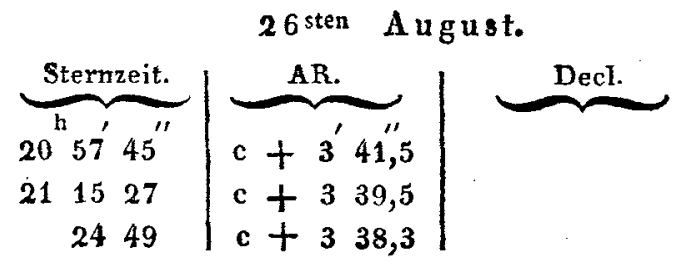

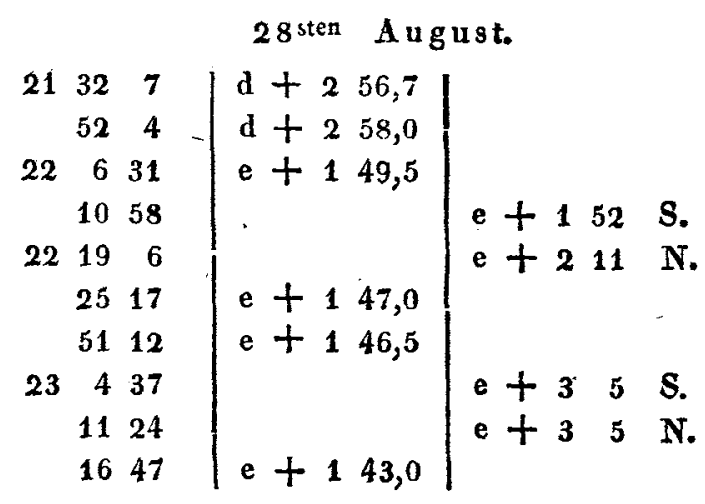

(Der Beschlufs folgt.)

Inh.: Auszug ans einem Schreiben des Herrn Capitains Henry Kater an den Herausgéber. p. 225. - Auszug aus einem Schreiben des Herrn Gambart an den Herausgeber. p. 225. - Auszug aus einem Schreiben des Herrn Prof. Encke an den Herausgeber. p. 227. - Auszug aus einem Schreiben des Herrn J. South F. R. S. an den Herausgeber. p. 227. - Schreiben des Herm J. F. $\mathscr{W}$. Herschel F. R. S. an den Herausgeber. p. 231. - Schreibèn des Herrn Prof. Argelander an den Herausgeber. p. 235. - Auszug aus einem Briefe des Hrn. Professors Argelander an Herrn Th. Clausen. p. 237. - Struve, Beobachtungen des letzten Cometen rom Jahre 1824 auf der Sternwarte in Dorpat angestellt. p. 239. 